See Article page XXX.

\section{Commentary: Getting it right}

\author{
Aaron Bettenhausen, MD, and Dawn S. Hui, MD
}

In this edition of The Journal, Fukuhara and colleagues ${ }^{1}$ describe the outcomes of aortic valve reintervention following transcatheter aortic valve replacement (TAVR). By analyzing patients from the Michigan Statewide quality collaborative, they found that 87 of 9694 $(0.90 \%)$ patients received reintervention following TAVR. The median time to reintervention was relatively short (9.6 months), and those who underwent surgical reintervention faced a high mortality rate of $15 \% .{ }^{1}$ The authors are congratulated for their reporting on this important issue. As TAVR indications have expanded and the absolute number of patients risen, this study makes clear that the prospect of reintervention should bear on initial decision-making. Annual TAVR procedures exceeded 70,000 in 2019 alone; thus, a not-insignificant number of patients will be affected by this issue. In the intermediate-risk clinical trials, aortic valve reintervention rates at 2 years were slightly greater than in Fukuhara and colleagues, at $1.4 \%$ for PARTNER II (Placement of AoRTic TraNscathetER Valves II) ${ }^{2}$ and $2.8 \%$ for SURTAVI (Surgical Replacement and Transcatheter Aortic Valve Implantation), ${ }^{3}$ compared with $0.6 \%$ and $0.7 \%$ in the respective surgical arms. The study by Fukuhara and colleagues lends insight into the complexity and risk of cases when TAVR explant is required. More than two-thirds of explant surgeries required major concurrent procedures, $29 \%$ had multiple combined procedures, and more than one-third of aortic repairs were unplanned. With odds-to-expected ratio for mortality being 1.8 , this suggests that the explant itself adds significant complexity and risk.

\footnotetext{
From the Department of Cardiothoracic Surgery, Joe R. and Teresa Lozano Long School of Medicine, University of Texas Health Science Center at San Antonio, San Antonio, Tex.

Disclosures: The authors reported no conflicts of interest.

The Journal policy requires editors and reviewers to disclose conflicts of interest and to decline handling or reviewing manuscripts for which they may have a conflict of interest. The editors and reviewers of this article have no conflicts of interest.

Received for publication Oct 5, 2021; revisions received Oct 5, 2021; accepted for publication Oct 7, 2021

Address for reprints: Dawn S. Hui, MD, 7703 Floyd Curl Dr, Suite 211L, San Antonio, TX 78229 (E-mail: dawn.hui@gmail.com).

J Thorac Cardiovasc Surg 2021; $\mathbf{\square}: 1-2$ 0022-5223/\$36.00

Copyright $(2021$ Published by Elsevier Inc. on behalf of The American Association for Thoracic Surgery

https://doi.org/10.1016/j.jtcvs.2021.10.012
}

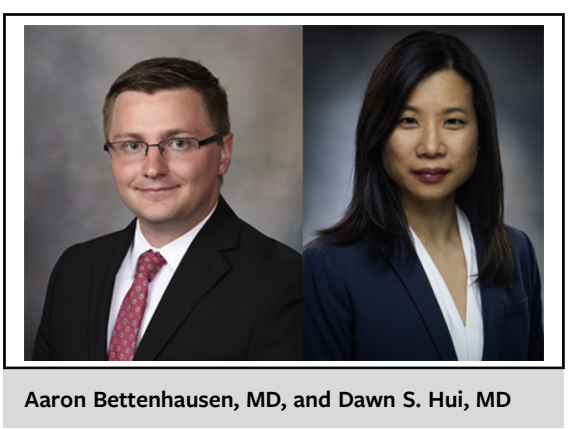

CENTRAL MESSAGE

A statewide study reveals the importance of assessing TAVR repeatability as part of the initial workup and decision for aortic valve patients, given the excess mortality associated with TAVR explant.

As technology continues to develop, cardiac surgeons find themselves at a crossroads. Initial TAVR trials focused on immediate safety and efficacy, but the rapid expansion of indications has outpaced considerations of implications for low- and intermediate-risk patients who are expected to have longer life expectancy. What hasn't changed for our discipline is providing longitudinal care for our patients. Balancing short-term results with long-term outcomes becomes even more challenging, as TAVR techniques have changed to mitigate TAVR complications. As the authors discuss, increasing use of self-expanding valves and higher implant position may be behind the rapid increase in TAVR explant volumes observed in their study. While these trends might result in better immediate TAVR results (lower pacemaker and paravalvular leak rates), there has been little attention to their impact on longer-term outcomes, including repeat TAVR implantability. The statewide findings of Fukuhara and colleagues, which mirror the national experience, ${ }^{4}$ suggest that the Heart Team should strongly weigh TAVR repeatability in its calculation of index therapy modality. This is another reason that Heart Teams everywhere must maintain a strong surgeon presence involved in all aspects of the preprocedural, intraprocedural, and postprocedural care of such patients. Data such as these contribute to our fund of knowledge and the pursuit 
of "getting it right," not just for "right now" but for the expected lifetime of the patient.

\section{References}

1. Fukuhara S, Tanaka D, Brescia A, Leung Wai Sang S, Grossman M, Sukul D, et al. Aortic valve reintervention in patient with failing transcatheter aortic bioprostheses: a statewide experience. J Thorac Cardiovasc Surg. August 31, 2021 [Epub ahead of print].
2. Leon MB, Smith CR, Mack MJ, Makkar RR, Svensson LG, Kodali SK, et al Transcatheter or surgical aortic-valve replacement in intermediate-risk patients N Engl J Med. 2016;347:1609-20.

3. Reardon MJ, Van Meighem NM, Popma JJ, Kleiman NS, Sondergaard L, Mumtaz M, et al. A. surgical or transcatheter aortic-valve replacement in intermediate-risk patients. $N$ Engl J Med. 2017;376:1321-31.

4. Fukuhara S, Brescia AA, Deeb GM. Surgical explantation of transcatheter aortic bioprostheses: an analysis from the Society of Thoracic Surgeons database. Circulation. 2020;142:2285-7. 